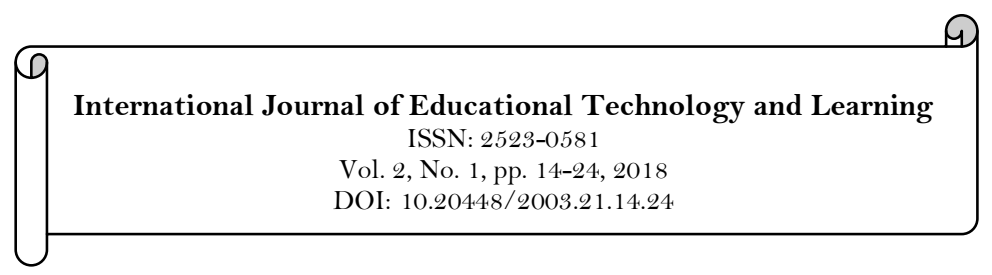

\title{
Student Cognitive Presence in Small Group Collaboration Facilitated by Mobile Instant Messaging
}

\author{
Yuhan QIAO' \\ Ying TANG ${ }^{2}$ \\ Khe Foon HEW ${ }^{3}$ \\ 1,2,3 The University of Hong Kong.
}

\begin{tabular}{l|l}
\multicolumn{3}{|c}{ Abstract } & \\
Cognitive presence describes the co-construction of knowledge in an & Keywords: \\
online learning community. Few previous studies examined the & Mobile instant messaging \\
development of cognitive presence in using mobile instant messaging & Community of inquiry. \\
(MIM) for academic purposes. Specifically, students nowadays set up & \\
small-size MIM discussion groups to work on group projects in & \\
higher education. No study has examined the establishment of & Licensed: \\
cognitive presence in these small groups. This paper reports a multi- & This work is licensed under a \\
case study, investigating three self-initiated discussion groups in & Creative Commons Attribution \\
higher education. Data were collected primarily from the online & License. \\
interactive records and students semi-structured interviews. The & \\
Community of Inquiry framework was utilized as the guidance for & Publisher: \\
coding process. The results show that students demonstrated & Scientific Publishing Institute \\
cognitive presence in the group discussions, yet only $36 \%$ of the total & \\
messages contained indicators of cognitive presence. The majority & \\
(64\%) of messages were on non-academic topics, such as greetings & \\
and casual social talks. In the interviews, we found students like \\
using MIM for social purposes, but not for academic purposes, due to \\
the social nature of MIM, the possible delayed responses, and the \\
lack of "facilitators".
\end{tabular}

\section{Introduction}

With the surging popularity of smartphones and easy connectivity to the Internet, users are now connected by various synchronous and asynchronous communication tools. Mobile instant messaging (MIM) applications, such as WhatsApp, Facebook Messenger and WeChat, are representing the new trend of communication. Since its emergence, MIM has become probably the most popular among all social networking tools. As of January 2017, WhatsApp announced more than 1.2 billion monthly active users (Statista, 2017) while WeChat hit 938 million till May 2017 (Tencent, 2017). Facilitated by the ubiquitous WiFi availability and data plan, users can exchange multiple modes of information, such as text messages, emotional icons, photographs, voice messages and videos, at no cost. MIM represents a new "quasisynchronous" mode of communication (Garcia \& Jacobs, 1999), facilitated by the pop-up notification on smartphone screens when new messages arrive. To explain, in quasi-synchronous communication, users can initiate a real-time conversation immediately as in a synchronous talk, or conduct interactions with time lag as in asynchronous communications.

Students not only take advantages of MIM services to stay connected socially, but also academically. Specifically, when students are assigned with group-based assignments, they would voluntarily set up MIM groups to stay connected-exchanging ideas, sharing materials and co-constructing products. Group assignment is an embodiment of "collaborative learning", which requires students to express, share and negotiate together, and to realize a common goal ultimately (Dillenbourg, 1999). The affordances of technological tools and serves have opened up new possibilities to advance collaborative learning. Yet the effect of using MIM in students' self-initiated group discussions has not been explored in previous studies.

In this study, we intend to look at the impact of MIM on student cognitive presence, following the Community of Inquiry (CoI) framework by Garrisons, Anderson, and Archer (2000). This framework aims 
evaluate the efficiency of online learning, approaching from three aspects: teaching, social and cognitive presence. Cognitive presence is defined as "the extent to which the participants in any particular configuration of a community of inquiry are able to construct meaning through sustained communication" (Garrisonn, Anderson, \& Archer, 2001). It mainly focuses on the knowledge sharing and co-construction, and manifests student cognitive thinking in the communication. As MIM is a social tool by nature, more studies focused on examining its impact on social presence rather than cognitive presence. We hope by conducting this study, the understanding towards cognitive presence will be furthered.

Therefore, this article presents a study exploring the establishment of cognitive presence in the discussion of student voluntarily established group chats. The following parts of this article are structured as follows: we discuss extant literature related to MIM use in education and cognitive presence development in the next section, and bring up research questions in section 3. Section 4 describes the research methodology, followed by a presentation of results and discussions subsequently in section 5 and 6 . We summarize the study and provide suggestions for future studies in section 7 .

\section{Literature Review}

\subsection{Mobile Instant Messaging in Education}

The prevalence of smartphones made MIM become the leading mobile communication services in recent years, replacing traditional text messaging services such as short message service (SMS) provided by cellular network carriers. Compared with other services and tools, MIM primarily concentrates on the immediate delivery of messages via a "pop-up" notification to present the message immediately (Quan-Haase, Cothrel, \& Wellman, 2005). The general characteristic of MIM can be summarized into the following: (1) users can access this kind of applications via handheld mobile devices such as smartphones, smartwatches, tablet computers etc., (2) messages can be transmitted by the Internet, not the telecommunication carriers, (3) connection between recipients can be bi-directional (one-to-one) and multi-directional (one-to-many) (So, 2016), (4) contact list can be customized by adding, deleting and blocking, (5) chat log can be saved (usually in the device), stored (usually in the cloud), cleared (not including the cache), deleted (including the cache).

Researchers are showing increasingly growing interest in exploring the use of MIM apps in education. Multiple studies have been done in various areas, including language teaching and learning medical teaching and learning (MI \& Meerasa, 2016), exam performance (Rau, Gao, \& Wu, 2008), collaborative discussion (Hou $\& \mathrm{Wu}, 2011)$, and administrative support (Naismith, 2007). Tang and Hew (2017) reviewed extant related literature and summarized the following ways in which MIM was used academically: 1) Journaling: using MIM for self-reflection; 2) Dialogic: using MIM to conduct either structured or free-flow conversations among participants; 3) Transmissive: using MIM for information dissemination; 4) Constructionist with peer feedback: using MIM to facilitate co-constructing a meaningful learning product; 5) Helpline: using MIM as a helpline platform to answer students' questions; 6) Assessment: using MIM to conduct summative assessment. Among the six ways of using MIM for teaching and learning, the dialogic use of it was proven the most frequent (Tang \& Hew, 2017). Facilitated by multiple technological affordances, including its multimodality, free-of-charge, flexibility and portability, MIM have provided channels for information flow and idea exchange that no other tools (e.g. laptops or desktop computers) can realize in our daily lives.

Most students expressed positive perceptions towards the incorporation of MIM in teaching and learning. Allagui (2014) used WhatsApp in an English foreign language class to help students practice structured conversations. For example, one student was prompted to send an invitation message to another student via WhatsApp, and the recipient was expected to reply to the invitation. The simulated communicative writing tasks received positive responses from students: $84 \%$ liked using WhatsApp for this class, $80 \%$ liked the task, and $94 \%$ said they would continue using WhatsApp in English in the future (Allagui, 2014). Similar favorable responses were also noticeable in Almekhlafy and Alzubi (2016), in which a group of Arabian students used WhatsApp to converse with four native English speakers. Students liked using WhatsApp in this way, and agreed it improved their confidence in using English (Almekhlafy \& Alzubi, 2016). On the other hand, several drawbacks were reported, including irrelevant or nonsensical messages in group chat (Bouhnik \& Deshen, 2014) and personal life being disrupted due to the mix-up of academic and social time (Rambe \& Bere, 2013).

Previous studies examined the use of MIM on the display of social presence in online learning process. Social presence is defined as the "the degree of salience of the other person in the interaction and the consequent salience of the interpersonal relationships" (Short, Williams, \& Christie, 1976). Higher level of social presence contributes to stronger sense of community in online learning, and it is positively related to student participative behaviors and perceptions (Gunawardena \& Zittle, 1997). Related to MIM use, studies have shown that it is easier to demonstrate social presence on MIM platforms compared to other forms of online communication, such as asynchronous online discussion forums (Tang \& Hew, 2017). Two possible reasons were provided by previous studies: the easy expression of emotions with emotional icons in MIM applications Wang, Fang, Han, and Chen (2016) and the possibility of immediate responses afforded by the notification function.

Cognitively, MIM has demonstrated strong potentials to improve learning outcomes, especially when it is used in dialogic activities (Tang \& Hew, 2017). For example, Lai (2016) compared student learning outcomes 
between the experimental group and the control group. Students in the experimental group would receive verbs with which they were expected to construct conversations on any topics using the verbs provided, while those in the control group did not receive such treatment. The results show that if students chatted with higher frequency, they would demonstrate higher levels of vocabulary gain (Lai, 2016). Another study was conducted by So (2016). The instructor would provide multimedia materials and reflective questions to students in a class WhatsApp group and encourage to students to answer questions, while the control group only received administrative help within the group. As a result, the experimental performed significantly better in the content test $(p<0.05)$.

Although the cognitive dimension of using MIM in education has been explored in previous studies, most of them dealt with outcomes. Little attention has been paid to the process in which cognition was developed. By far, only one study (Wang et al., 2016) examined the cognitive presence in the learning process, when knowledge was communicated and constructed together among students. Wang et al. (2016) discussed two characteristics of MIM-enabled cognitive presence: easy to reach resolution and effective negotiation of meanings, facilitated by the availability of both audio and text chats. This study discussed all three dimensions of CoI, namely the teaching, social and cognitive presence in language learning. Our study, on the other hand, will focus on only cognitive presence in students' authentic communication in self-initiated group discussions.

\subsection{Cognitive Presence}

Garrisons et al. (2000) proposed a generic Community of Inquiry model to analyze educational practices and experience facilitated by online communication media. This model was then widely applied in virtual environments, such as computer conferencing and asynchronous text-based group discussions, and distance educational settings. CoI is comprised of three interdependent elements Figure 1 namely teaching presence, social presence, and cognitive presence. Teaching presence is mainly about the design and facilitation of course instruction, and social presence is primarily about the interpersonal relationships among online participants (Garrisons et al., 2000). Cognitive presence, according Garrisons et al. (2000), refers to "the extent to which learners are able to construct and confirm meaning through sustained reflection and discourse in a critical community of inquiry" (p. 1). Drawing upon this definition, cognitive presence emphasized on both intrapersonal thinking and inter-personal communication.

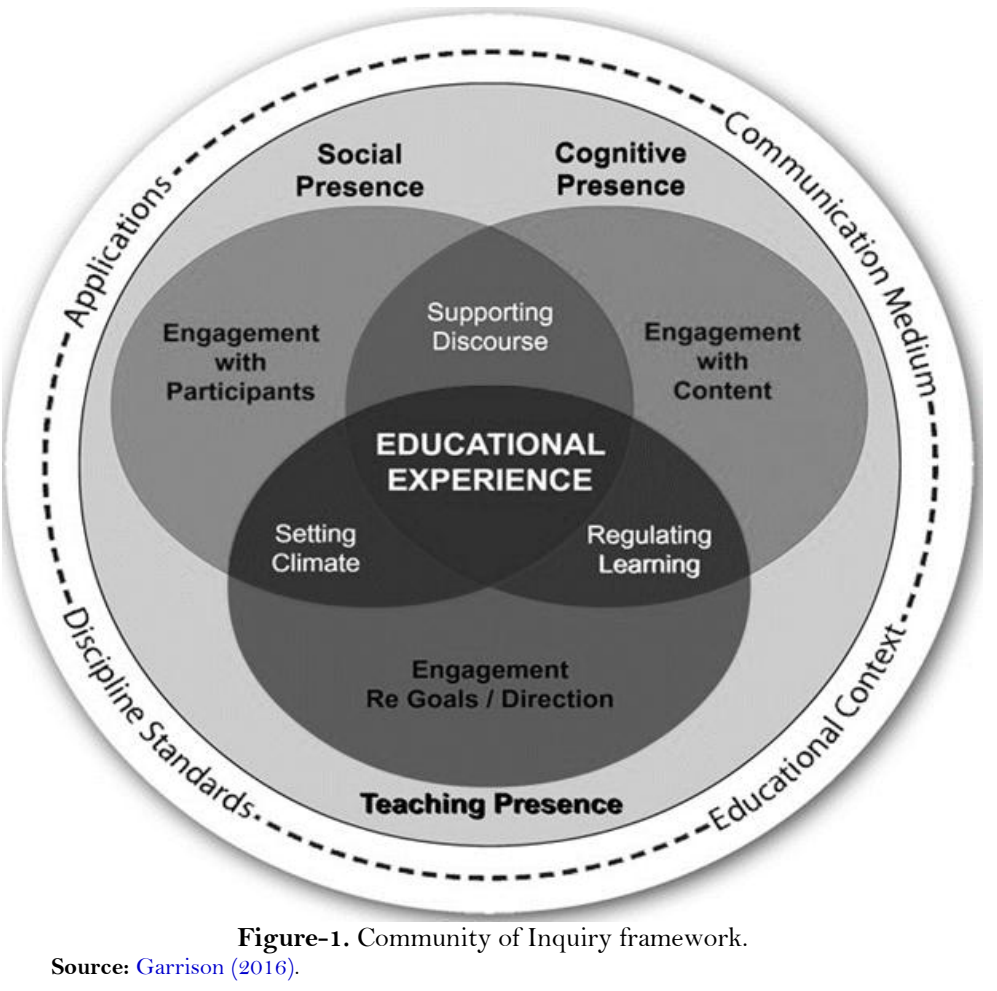

Cognitive presence is operationalized by the practical inquiry model (Garrisons et al., 2000). This model is aligned along two axes: action/deliberation \& perception/conception, which reflects the relationship between practice and cognition, and between shared and personal worlds Figure 2 (Garrisons et al., 2000). This model outlines four phases of cognitive presence, to indicate a logical critical thinking process. The four phases are: 1) triggering events, 2) exploration, 3 ) integration and 4) resolution. 


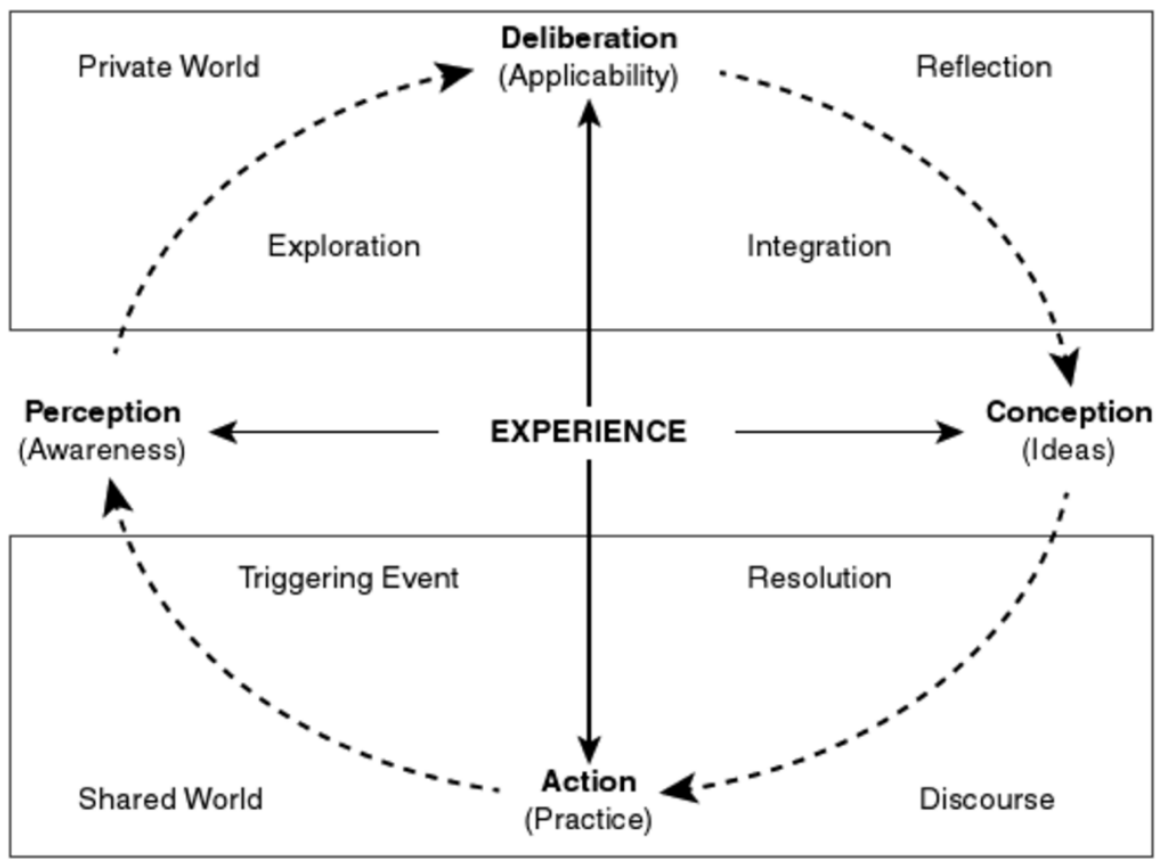

Source: Garrisons et al. (2000).

Figure-2. Practical Inquiry model.

The first phase is triggering event which can be assumed as the initiation phase of practical inquiry. Normally, an argument, obstacle or dilemma can be identified from the educational experience as the triggering event. In the traditional learning environment, teachers might typically employ explicit expectations or assignments as the triggering event while in the computer conferencing context, a particularly democratic and nonhierarchical atmosphere, all the participants from the learning community could raise problems as the triggering event to the discourse, which might probably engage participants, embark the knowledge acquisition process and develop unintentional but formative understanding.

The second phase is exploration that participants shift between the private and shared world by reflecting understanding individually and searching information collaboratively. At the beginning of this phase, participants are strongly suggested to distinguish and comprehend the nature of their problems then probe for relevant information and evidence, which might happen "through group activities and brainstorming and/or through more private activities such as literature searches" (Garrison, 2016). In a learning community, participants contrive iteratively constructing knowledge between the private and shared world which means they build perception between critical reflection and discourse (Garrisonn et al., 2001) by searching information, exchanging opinions, questioning assumptions, challenging ideas and generating impressions. After this recursive operation, students might filter the appropriate data relevant to their problems. During this process, the original academic task which may be assumed as teaching presence acts as a monitor, manager and leader guiding the disparate judgments moving to the next phase, integration.

The third phase is integration, a transaction from exploration, participants may more concentrate on constructing meaning. The focus of this phase is how to describe their ideas or consideration and then integrate the findings in proper formation and sequence. As participants are considerably involving in the critical discourse at this phase, it is more arduous to detect the commencement and completion of this phase. It supposed that participants might deepen comprehension and shape perception in this phase still it depends on the information collected from the exploration phase. Literally, there should be a mini-circulation between exploration and integration phase. Normally, when generating new awareness, serval round of information searching and confirming as well as recognition shaping and constructing towards a particular segment of the general educational challenges may be applied during these two phases. Moreover, teaching presence is typically required as it could "diagnose misconception, provide probing questions comments and additional information in an effort to ensure continuing cognitive development and to model the critical thinking process" (Garrisonn et al., 2001).

The fourth phase is resolution of the argument, obstacle or dilemma, "whether reducing complexity by constructing order or discovering a contextually specific solution to a defined problem" (Garrison, 2016) directly or vicariously. For daily routine, suggesting explication or validating assumption may be more practical while for academic challenge, direct confirmation seems more unfeasible. Nevertheless, in the online learning settings, participants from the learning community "operating out of work or family contexts, direct applications and testing may be more realistic" (Garrison, 2016) such as meditation attempts or consent invention within the community. Leading with specific expectations, participants tend to validate conjecture or 
evaluate proposition, "and treatment of content from a critical perspective" (Garrison, 2016). Eventually, further questions might be proposed, which encourage the participants of the learning community to discover more profitable information, triggering extra rounds of critical inquiry then promoting constant learning.

To better explain the four phases, Table 1 presents the descriptors (adjectives characterizing process), indicators (manifest examples) and authentic examples that occurred in real interactions. The descriptors and indicators were proposed by Garrisons et al. (2000) to facilitate the assessment of critical thinking being aligned with the developmental phases.

Table-1. Descriptors, indicators and examples of the four phases

\begin{tabular}{l|l|l|l}
\hline Phase & Descriptor & Indicator & Example \\
\hline $\begin{array}{l}\text { Triggering } \\
\text { Event }\end{array}$ & $\begin{array}{l}\text { Evocative } \\
\text { (Inductive) }\end{array}$ & $\begin{array}{l}\text { Recognize } \\
\text { Problem } \\
\text { Puzzlement }\end{array}$ & $\begin{array}{l}\text { "It has been argued that the only way to deliver effective } \\
\text { e-learning is through a Community of Inquiry model or } \\
\text { approach. Why do you think that is?" }\end{array}$ \\
\hline Integration & $\begin{array}{l}\text { Tentative } \\
\text { (Divergent) }\end{array}$ & $\begin{array}{l}\text { Divergence } \\
\text { Info Exchange } \\
\text { Suggestions } \\
\text { Brainstorming } \\
\text { Intuitive Leaps }\end{array}$ & $\begin{array}{l}\text { "One reason I think learning communities are seldom } \\
\text { used is that it is too complicated to engage participants } \\
\text { collaboratively. Another may be the mindset of those in } \\
\text { charge to change practices." }\end{array}$ \\
\hline Resolution & $\begin{array}{l}\text { Convergence } \\
\text { Synthesis } \\
\text { Solutions }\end{array}$ & $\begin{array}{l}\text { "We also had trouble getting cooperation. Often the use } \\
\text { of new tools requires new organizational structures. We } \\
\text { addressed these issues when we implemented a systems } \\
\text { approach, and I think that's why we were successful." }\end{array}$ \\
\hline Source: Garrisons & $\begin{array}{l}\text { Apply } \\
\text { Test } \\
\text { Defend }\end{array}$ & $\begin{array}{l}\text { "A good test would be to ensure that participants } \\
\text { understand the expectations, and that collaboration is } \\
\text { properly rewarded. Once implemented, this could be } \\
\text { assessed by considering project grades as well as the } \\
\text { impressions of the participants." }\end{array}$ \\
\hline
\end{tabular}

Multiple studies have been done on examining cognitive presence levels, guided by the practical inquiry model. Yet most of them were conducted in asynchronous environment, such as online discussion forums. For example, Darabi, Arrastia, Nelson, Cornille, and Liang (2011) studied asynchronous online discussions and compared four discussion strategies (structured, scaffolded, debate and role play) in terms of the establishment of cognitive presence. The results suggested that the scaffolded strategy was strongly associated with resolution phase, while debate and role-play were highly associated with exploration and integration phases. Similarly, Lee (2014) analyzed 674 online discussion forum messages using the CoI model, and social presence was positively related to the quality of cognitive presence. De, Dolmans, Jobsis, Muijtjens, and van (2009) developed an e-learning model, and suggested that more time was needed for critical thinking stages, i.e. the integration and resolution phases (Kanuka, Rourke, \& Laflamme, 2007). By far only Wang et al. (2016) examined all three dimensions of CoI, including cognitive presence in quasi-synchronous communication enabled by mobile instant messaging. Our understanding towards this topic of interest is still limited.

The following two research questions are proposed to guide the current study. 1 . What levels of cognitive presence were demonstrated in the quasi-synchronous online small-group discussions facilitated by using WhatsApp and WeChat? 2. How do students perceive using WhatsApp and WeChat for academic purposes?

\section{Methodology}

A multi-case study was conducted in a large Asian public university, in three student-self-initiated MIM groups for academic purposes. According to (Yin, 2003), multiple-case study following a "replication logic" to reveal support for theoretically which underlying the utilization of it should fulfill either (1) predicting similar results (literal replication) or (2) producing contrasting results but for predictable reasons (theoretical replication) (Lees \& Rine, 2004; Zucker, 2009). Cases were chosen based on convenient sampling, and on voluntary basis. The three groups, involving 9 students, came from three different master level courses in education respectively. All three courses were offered once a week for 8 weeks. Course A was carried out from September to November 2016 while Course B and C spanned from January to March 2017. English was the instructional language, and also the second language for all of participants in this study. Table 2 described the contexts, participants and task information for all three cases. 
Table-2. Description of cases

\begin{tabular}{|c|c|c|c|c|}
\hline & Duration & MIM used & Group assignments & No. of students \\
\hline Group A & 2016 fall & WhatsApp & $\begin{array}{l}\text { 1. Designing and implementing a learning } \\
\text { activity with at least one educational } \\
\text { technology. } \\
\text { 2. Presenting various learning activities } \\
\text { assigned over the semester in a blog e- } \\
\text { portfolio. } \\
\text { 3. Designing a webpage for weekly reflection. }\end{array}$ & 4 \\
\hline Group B & $\begin{array}{l}2017 \\
\text { spring }\end{array}$ & WeChat & $\begin{array}{l}\text { In groups, designing an instructional product (e.g. } \\
\text { apps), presenting its design and theoretical } \\
\text { underpinnings in a } 20 \text {-minutes presentation video, } \\
\text { and submitting a written report. }\end{array}$ & 4 \\
\hline Group C & $\begin{array}{l}2017 \\
\text { spring }\end{array}$ & WeChat & $\begin{array}{l}\text { 1. In groups, designing a course based on one } \\
\text { adult learning strategy learned in the course. } \\
\text { In groups, demonstrating one adult learning } \\
\text { strategy implementation in a role-play } \\
\text { scenario. }\end{array}$ & 4 \\
\hline
\end{tabular}

\subsection{Data Collection}

Data were primarily collected from two sources: group chat records and semi-structured interview. Both WeChat and WhatsApp can store message records in the smartphone storage or using the cloud service. Therefore, we were able to retrieve all historical records with the consent of all participants involved. To understand students' perception towards using MIM for academic discussions, semi-structured interviews were conducted with 4 participants on the voluntary basis. Comparing to rigorous structured interview with the specific set of questions, semi-structured interviews allow the researchers to not only probe certain predetermined inquiries necessarily but also have the opportunities and alternatives to developing further issues spontaneously during the interaction with the interviewees by observation. The interview questions focused on the following aspects: (1) students' familiarity of WhatsApp and WeChat as learning tools; (2) students' understanding and expectations of using WhatsApp and WeChat before, during and after class; (3) advantages and disadvantages of applying WhatsApp and WeChat for academic purposes; (5) students' comments and suggestions of adopting WhatsApp and WeChat in the educational context.

\subsection{Data Analysis}

The unit of analysis adopted in this study was each message sent by individual student. Content analysis was implemented to analyze data obtained. Specifically, the practical inquiry model (Garrisons et al., 2000) was referred to code the online interactive records. As students not only discussed academically related matters in the group chat, we added a fifth category "non-cognitive" to better organize the coding process. Table 3 summarizes the codes used in this study.

Table-3. Codes for data analysis.

\begin{tabular}{|c|c|c|c|}
\hline \multicolumn{2}{|l|}{ Category } & Indicators & ID \\
\hline \multirow{15}{*}{$\begin{array}{l}\text { Cognitive } \\
\text { Presence }\end{array}$} & \multirow{2}{*}{$\begin{array}{l}\text { Triggering } \\
\text { Events }\end{array}$} & Recognizing or distinguishing problem, obstacle or dilemma & $\mathrm{T} 1$ \\
\hline & & Describing sense of puzzlement, confusion, hesitation & $\mathrm{T} 2$ \\
\hline & \multirow[t]{5}{*}{ Exploration } & $\begin{array}{l}\text { Proposing associated background information corresponded to discussion } \\
\text { subject }\end{array}$ & E1 \\
\hline & & Adding to established points but does not systematically defend/justify/develop & $\mathrm{E} 2$ \\
\hline & & Initiating suggestions towards discussion subject & E3 \\
\hline & & Questioning towards exploration and seeking for certain information & E4 \\
\hline & & Offering unsupported opinions & E5 \\
\hline & \multirow[t]{5}{*}{ Integration } & Searching possible solutions, applications or conclusions & I1 \\
\hline & & Building on solutions or conclusions or abstracting conversation & $\mathrm{I} 2$ \\
\hline & & Committing on prior message followed by substantiated agreement & I3 \\
\hline & & Connecting and integrating multiple types of information from different sources & $\mathrm{I} 4$ \\
\hline & & Rationalizing on potential solutions and conclusions & I5 \\
\hline & \multirow[t]{3}{*}{ Resolution } & Suggesting application scheme or proposal & $\mathrm{R} 1$ \\
\hline & & Justifying, defending, critiquing, clarifying solutions or conclusions & $\mathrm{R} 2$ \\
\hline & & Acknowledging solutions or conclusions & $\mathrm{R} 3$ \\
\hline \multirow{4}{*}{\multicolumn{2}{|c|}{ Non-cognitive Presence }} & Presenting phatic communication or greeting & $\mathrm{N} 1$ \\
\hline & & Requiring real-time information or specific request & $\mathrm{N} 2$ \\
\hline & & Encouraging & $\mathrm{N} 3$ \\
\hline & & Not coded & $\mathrm{N} 4$ \\
\hline
\end{tabular}

Source: Adapted from Garrisonn et al. (2001) and Rodriguez (2014). 
Two coders, the first author and a graduate student helper, coded the three sets of online discussion transcripts. Certain training was provided to the second coders including interpreting the theoretical framework and demonstrating the coding scheme. Holsti (1969) coefficient of reliability (CR) was calculated, and the result reached $90 \%$. All disagreement was resolved through discussion.

\section{Results}

\subsection{Coding Results}

A total of 1897 messages were retrieved from the three separate online discussions, in which 369 messages were obtained from Group A, 907 from Group B and 621 from Group C. Results are displayed in Table 4. Overall, the messages coded for the four phases of cognitive presence and non-cognitive presence make up $3.32 \%$ in triggering events, $6.11 \%$ in exploration, $21.61 \%$ in integration, $1.21 \%$ in resolution and $64.00 \%$ in non-cognitive presence.

Table-4. Summary of coding results.

\begin{tabular}{|c|c|c|c|c|c|c|c|c|c|c|}
\hline \multicolumn{2}{|l|}{ Category } & \multirow{3}{*}{$\begin{array}{l}\text { ID } \\
\mathrm{T} 1\end{array}$} & \multicolumn{2}{|c|}{ Group A } & \multicolumn{2}{|c|}{ Group B } & \multicolumn{2}{|c|}{ Group C } & \multicolumn{2}{|c|}{ Overall } \\
\hline & & & \multirow{2}{*}{$\frac{f}{7}$} & & \multirow{2}{*}{$\frac{f}{5}$} & \multirow{2}{*}{$\begin{array}{l}\% \\
0.56\end{array}$} & \multirow{2}{*}{$\frac{f}{10}$} & \multirow{2}{*}{$\begin{array}{l}\% \\
1.62\end{array}$} & \multirow{2}{*}{$\frac{f}{22}$} & \multirow{2}{*}{$\begin{array}{l}\frac{\%}{1.16} \\
\end{array}$} \\
\hline Cognitive & Triggering & & & & & & & & & \\
\hline \multirow{18}{*}{ Presence } & \multirow[t]{2}{*}{ Events } & $\mathrm{T} 2$ & 25 & 6.77 & 11 & 1.21 & 5 & 0.81 & 41 & 2.16 \\
\hline & & $\begin{array}{l}\text { Sub- } \\
\text { total }\end{array}$ & 32 & 8.67 & 16 & 1.77 & 15 & 2.43 & 63 & 3.32 \\
\hline & \multirow{6}{*}{ Exploration } & E1 & 15 & 4.06 & 10 & 1.10 & 8 & 1.29 & 33 & 1.74 \\
\hline & & $\mathrm{E} 2$ & 4 & 1.08 & 7 & 0.77 & 7 & 1.13 & 18 & 0.95 \\
\hline & & E3 & 4 & 1.08 & 2 & 0.22 & 9 & 1.45 & 15 & 0.79 \\
\hline & & $\mathrm{E} 4$ & 2 & 0.54 & 4 & 0.44 & 16 & 2.58 & 22 & 1.16 \\
\hline & & E5 & 5 & 1.36 & 5 & 0.56 & 18 & 2.88 & 28 & 1.48 \\
\hline & & $\begin{array}{l}\text { Sub- } \\
\text { total }\end{array}$ & 30 & 8.13 & 28 & 3.09 & 58 & 9.33 & 116 & 6.11 \\
\hline & \multirow[t]{6}{*}{ Integration } & I1 & 6 & 1.63 & 3 & 0.33 & 14 & 2.25 & 23 & 1.21 \\
\hline & & $\mathrm{I} 2$ & 15 & 4.06 & 10 & 1.10 & 37 & 5.96 & 62 & 3.27 \\
\hline & & I3 & 17 & 4.61 & 98 & 10.80 & 50 & 8.05 & 165 & 8.70 \\
\hline & & $\mathrm{I} 4$ & 19 & 5.15 & 58 & 6.39 & 51 & 8.21 & 128 & 6.75 \\
\hline & & $\mathrm{I} 5$ & 20 & 5.42 & 8 & 0.88 & 4 & 0.64 & 32 & 1.69 \\
\hline & & $\begin{array}{l}\text { Sub- } \\
\text { total }\end{array}$ & 77 & 20.87 & 177 & 19.50 & 156 & 25.11 & 410 & 21.61 \\
\hline & \multirow[t]{4}{*}{ Resolution } & $\mathrm{R} 1$ & 9 & 2.44 & 8 & 0.88 & 6 & 0.96 & 23 & 1.21 \\
\hline & & $\mathrm{R} 2$ & 13 & 3.52 & 2 & 0.22 & 6 & 0.96 & 21 & 1.11 \\
\hline & & R3 & 18 & 4.88 & 5 & 0.56 & 27 & 4.35 & 50 & 2.64 \\
\hline & & $\begin{array}{l}\text { Sub- } \\
\text { total }\end{array}$ & 40 & 10.84 & 15 & 1.66 & 39 & 6.27 & 94 & 4.96 \\
\hline \multirow{5}{*}{\multicolumn{2}{|c|}{ Non-cognitive Presence }} & $\mathrm{N} 1$ & 16 & 4.34 & 5 & 0.55 & 2 & 0.32 & 23 & 1.21 \\
\hline & & $\mathrm{N} 2$ & 110 & 29.81 & 599 & 66.04 & 336 & 54.11 & 1045 & 55.09 \\
\hline & & N3 & 42 & 11.38 & 52 & 5.73 & 10 & 1.62 & 104 & 5.48 \\
\hline & & $\mathrm{N} 4$ & 22 & 5.96 & 15 & 1.66 & 5 & 0.81 & 42 & 2.21 \\
\hline & & $\begin{array}{l}\text { Sub- } \\
\text { total }\end{array}$ & 190 & 51.49 & 671 & 73.98 & 353 & 56.86 & 1214 & 64.00 \\
\hline \multicolumn{3}{|l|}{ Total } & 369 & 100.00 & 907 & 100.00 & 621 & 100.00 & 1897 & 100.00 \\
\hline
\end{tabular}

Non-cognitive presence accounts for 64 percent of the total messages which primarily contains the following aspects:

(1) Phatic communication and greeting, which participants released messages entirely for the purpose of the social networking, but not for knowledge construction, some of which are saluting, expressing friendly, celebrating or validating existence etc.

$$
\text { E.g. "Hi, good morning , everyone! Is anyone online?" }
$$

(2) Course notification or assignment reminder, which participants broadcasted within the learning community to inform the group mates to do something or not to do something, for example remember to submit essays before the deadline, notify the classroom avenue had changed etc.

E.g. "Just a reminder, please remember to update the reflection today $\theta$. Thanks."

(3) Schedule arrangement, which participants consult together determining when and where to hold the next appointment out of instructional time. 
E.g. "Will everyone available tomorrow afternoon? How about we have a short meeting during lunch time in the student union canteen outdoor area? Let's talk about our group assignment!"

(4) Real-time information inquiry and update, which participants required for immediate responses from their group mates including navigating, confirming locations, ordering meals etc.

E.g. "Guys, I can't find discussion room 6. Could you please help me? By the way, would you want some drinks or cakes? I can bring them to you $\because \mathbf{O}$."

(5) Encouragement and gratitude, which participants normally motivate each other to toil before the due date or express their appreciation after receiving guidance or assistant.

E.g. "Come on dudes! Let's finish this essay this morning ! I will be appreciated if you send me your email address so I could forward the instruction to you. Thanks!"

(6) Non-academic information sharing, which participants gossiping and "chit chatting" completely for pleasure towards random topics such as diet, entertainment, traveling, career planning etc.

E.g. "Well, I am currently not in Hong Kong. I wanna look for jobs in my hometown. Talk later? I am having dinner with my friends outside $\Theta . "$

Integration (21.61\%) places the second, with the following sub-topics:

(1) Potential solutions, applications or conclusions investigation, which participants generated prospective settlement proposition regarding specific research questions, such as proposing thematic suggestions for final group presentation etc.

E.g. "Do anyone have a better idea of the simulated course presentation? How about table etiquette? First aid?

Photography? Let's brainstorming

(2) Conversation recapitulation, which a latent group leader summarized the opinions proposed by participants for the purpose of achieving objectives by stages.

E.g. "Based on what we have discussed, the top three potential topics are health planning, photograph, logical thinking."

(3) Critiquing or commenting towards suggested resolution provision, which participants expressed their judgments or outlooks to the previous solving scheme.

E.g. "Personally, I think we should not introduce self-directed learning at the very beginning of our course that will leave nothing to teach for the last 10 minutes --."

(4) Blending and integrating multiple types of information from different sources, which participants may generate underlying strategies through various approaches such as literature review, hands-on practice, observation etc.

E.g. "Guys, please visit this website. Here is the link. They have plenty of pictures and videos introducing the three components of photography which could help us to select our subtopic."

(5) Justifying potential solutions and conclusions, which participants rationalized their preference on certain proposal which might develop into the final resolution.

E.g. "I prefer to teach photography instead of logical thinking since nobody here is an expert in cognition construction and thinking is kind of "invisible and untouchable" which makes me feel quite stressful and insecure to teach to the class 3 ."

Exploration (6.11\%) comprises the following elements:

(1) Searching relevant background information related to the discussion topic, which participants investigating general facts or evidence via multiple approaches.

E.g. "Please refer to this website and watch the video. I reckon that we could stimulate the way they do the storytelling:"

(2) Brainstorming, which participants generated ideas seeking conclusion or resolution towards specific questions creatively and spontaneously.

E.g. "How about teaching JAVA?", "I think scratch could be a better choice ๑.", "But not everyone is interested in programming! How about something fun and useful, such as video editing?"

(3) Initiating possible suggestions or solutions towards discussion topics, which participants raised subjective presumptions or opinions tentatively.

E.g. "How about we choose Facebook as our research objective? Since social media is the best representative of

Web 2.0, well, Facebook is the most popular social media application worldwide."

(4) Raising suggestions for considerations, which participants explicitly illustrated message as exploration.

E.g. "Do I interpret it in the right way $(\bullet)$

(5) Presenting unsubstantiated viewpoints, which participants proposed all the potential approaches but without evaluation or assessment.

E.g. "So the theme for our storytelling video could be the "bomb quiz", "Russian roulette", "equality and equity question", "the origin of the Dragon Boat Festival", what's more?" 
Triggering events $(\mathbf{3 . 3 2} \%)$ ranks penultimate among the five categories, which basically consisted of the following segments:

(1) Recognizing or distinguishing problem, obstacle or dilemma, which participants might question about phenomenon, statements or ideas etc.

E.g. "Since we choose the "bomb quiz" as our storytelling theme, how will we discard it subsequently?"

(2) Expressing a sense of puzzlement or hesitation, which participants probably not ask questions directly but they do represent confusion towards specific occurrences or judgments.

E.g. "I have found some rubrics online but seems most of them are designed for the professional photography with the camera rather than the mobile phone. I am not sure whether it is workable for mobile photography or not $x$

Resolution (1.21\%) constitutes the minimal proportion that comprises of the following sections:

(1) Proposing possible application scheme or utilization suggestion, which participants raised feasible or practical approach with the major agreement.

E.g. "I believe that we should hold the photography one as our topic instead of the logical thinking one. What do you think $\odot$ ?"

(2) Defending or criticizing nearly established solution proposition or conclusion recommendation, which participants declared the reasons why they support or against the specific decision.

E.g. "Since we have an expert in this field which she could explain clearly to the audience how to use the three basic rules when taking photos. Think about it! Everyone wants nice photos! We can fulfill what they want!"

(3) Resolution acknowledgment or conclusion confirmation, which participants eventually reach consensuses in favor of generally accepted plan or proposition.

E.g. "Alright, so we are going to introduce photography? Seems you three like it so much. I am all right with that 0 ."

\subsection{Interview Results}

Semi-structured interviews were conducted with four postgraduate students, endeavoring to understand to what extent were students engaged in the learning community through WhatsApp and WeChat as well as how students perceived utilizing these applications for academic purposes. Students' opinions were summarized into the following major topics.

(1) Students are familiar with communicating with either WhatsApp or WeChat, and they highly welcomed the utilization of MIM apps in and after classroom. However, they did not distinctly understand the expectations of the academic potentials of these apps.

E.g. "The first time I installed WeChat is because my friends introduced it to me. At that time, I only use it as a communication app but not learning tool. When I studied in HKU, some of my classmates live far from the campus, so someone established an online discussion group. I don't know why, but it just happened. After that, I find it is an efficient way to communicate with others."

(2) MIM apps served as supplemental tools rather than principal approaches, which participants expressed that they considered MIM apps as an additional method to interact with peers. If they could assemble offline, they will definitely discard discussing online.

E.g. "I may use WeChat or WhatsApp to keep in touch with my group mates since it convenient for us because not everyone checks email or Moodle every day. However, I prefer meeting them in the real world instead of totally online. It is better to meet someone in person. "

(3) MIM communication sometimes lacked in-depth explication and organization, which might hinder recipients' interpretation of the messages.

E.g. "As for me, although chatting on WeChat seems "saving time", I am wondering is it really looks that great? I sometimes find it making me annoyed when someone sends me several super long text or voice messages. rou know, when people talking, they do not really compose it very well. But when you tape it down, this process helps you to reflect. What's more, when someone mentioned my name in the middle of a discussion, it takes me more time to look through all the chatting log to "locate" who and when mentioned me. So, I prefer face-to-face discussion when I want to explain something serious and important."

(4) MIM was specifically facilitative to delivering emotional support, which was beneficial for expressing encouragement and team building.

E.g. "When we have a group assignment to finish, we always divide the task into serval parts, so everyone needs to complete their own jobs in limited time. I sometimes feel quite nervous and anxious, but my group mates always try to help and encourage me. I feel quite relieved when I know I have someone at my back. Through MIM apps, I know that I have comrades in arms who are always supporting me that means more than simply sharing information then accomplish the homework." 
(5) MIM has the possibility of privacy leak. Participants expressed that they may concern about the security of information.

E.g. "I am a little bit afraid of my personal information leaking out. There is no adequate supervision during the communication process."

(6) Participants did not have any constructive suggestions to use MIM apps for academic purposes.

E.g. "Well, actually I don't have any suggestion. I think that WeChat or WhatsApp is good for us to interact with peers that already fulfill my expectation towards this kind of communication tool. I feel quite satisfied with them."

\section{Discussion}

The results showed that the total percentage of cognitive presence, including integration, exploration and triggering events, constitutes roughly one-third of the messages, while non-cognitive presence comprises the majority of the retrieved transpires. Almost all the participants expressed that WhatsApp and WeChat probably are their foremost alternatives when they have the requirements for interacting with peers about casual social topics, but not for academic interactions. They prefer synchronous approaches such as making phone calls directly or launching voice or video calls provided by WhatsApp, WeChat or Google Hangouts instead of sending and receiving text or audio threads.

Despite the fact the quasi-synchronous communicative mode affords great flexibility for communication, it may also cause some problems. In the online environment, users will not feel as compulsory to "respond" immediately as in a face-to-face context or in a synchronous communication such as phone call. In other words, it is purely the recipient's decision to carry on the conversation or not. One interviewee expressed that it is sometimes frustrating to wait for peers exchanging their perspectives which result in interrupting the "train of thought" unconsciously.

The lack of "teaching" presence, displayed by either the instructors or student facilitators, might be another reason for the low level of cognitive presence in this situation. The discussion groups were established by students voluntarily, thus teaching presence was absent. However, a facilitator plays a critical role to manage and steer the interactions in online communications (Hew \& Cheung, 2012). One interviewee emphasized that in order to accelerate the learning process, it is highly recommended to nominate a participant as the administrator in the learning community, intending to develop weekly study routine, outline meeting minutes, enhance purposeful communication and promote in-depth learning. The emerging role of student facilitator in voluntary small MIM groups might be an interesting topic to explore in the future.

The presumed role of MIM is primarily a social tool. Therefore, its educational potentials have not been adequately explored and accepted. Comparing to email or Moodle online discussion forum, which are used daily for educational purposes, MIM is perceived as not "academic" or "formal" for educational talks. Students are not familiar with using it for non-social purposes, and they are not sure whether or how they can take advantages of the tool to possibly facilitate learning. An interviewee mentioned that email is definitely the prime and exclusive approach to communicate with instructors or peers for significant dialogues.

This study has some limitations. First, the study analyzed a small sample size including 1897 messages retrieved and analyzed from 3 separate courses via WhatsApp and WeChat, which limits the generalizability of the study results. Second, we only examined cognitive presence in this study. The CoI framework introduced three dimensions of online discussions. It would be interesting to explore the social presence and teaching presence level, and how these three dimensions interact and influence one another. Additionally, future studies may examine the role and communicative functions of emoticons, emoji and stickers in online communication. The prevalence of using these graphic icons has been prominent in students' communication in our study. Few study has examined this topic of interest in students' self-initiated discussion groups,

\section{Conclusion}

This study examined levels of cognitive presence in three student self-initiated online discussion groups on WeChat and WhatsApp, two quasi-synchronous mobile instant messaging tools. Garrisons et al. (2000) community of inquiry framework was utilized to analyze the interactive records to find out to what extent students demonstrated cognitive presence in this context. We also interviewed four participants, asking for their perception and attitude towards using MIM for academic communication. The results show that students demonstrated cognitive presence in the group discussions, yet only $36 \%$ of the total messages contained indicators of cognitive presence. The majority (64\%) of messages were on non-academic topics, such as greetings and casual social talks. In the interviews, we found students like using MIM for social purposes, but not for academic purposes, due to the social nature of MIM, the possible delayed responses, and the lack of "facilitators".

\section{References}

Allagui, B. (2014). Writing through WhatsApp: An evaluation of students writing performance. International Journal of Mobile Learning and Organisation, 8(3-4), 216-231. 
Almekhlafy, A., \& Alzubi, A. A. F. (2016). Mobile-mediated communication a tool for language exposure in EFL informal learning settings. Arab World English Journal 7(1), 388-407.

Bouhnik, D., \& Deshen, M. (2014). WhatsApp goes to school: Mobile instant messaging between teachers and students. Journal of Information Technology Education: Research 13, 217-231.

Darabi, A., Arrastia, M. C., Nelson, D. W., Cornille, T., \& Liang, X. (2011). Cognitive presence in asynchronous online learning: A comparison of four discussion strategies. Journal of Computer Assisted Learning, 27(3), 216-227.

De, L. B. A., Dolmans, D. H., Jobsis, R., Muijtjens, A. M., \& van, d. V. C. P. (2009). Exploration of an e-learning model to foster critical thinking on basic science concepts during work placements. Computers E̊ Education, 53, 1-13.

Dillenbourg, P. (1999). Collaborative learning: Cognitive and computational approaches. In Dillenbourg, P: (Ed.). Pergamon, Elsevier Science.

Garcia, A. C., \& Jacobs, J. B. (1999). The eyes of the beholder: Understanding the turn-taking system in quasi-synchronous computer-mediated communication. Research on Language and Social Interaction, Available at: https://doi.org/10.1207/S15327973rls3204_2,32(4), 337-367.

Garrison, D. R. (2016). E-learning in the 21st century: A community of inquiry framework for research and practice: Taylor \& Francis.

Garrisonn, D. R., Anderson, T., \& Archer, W. (2001). Critical thinking, cognitive presence, and computer conferencing in distance education. American Journal of Distance Education, 15(1), 7-23.

Garrisons, D. R., Anderson, T., \& Archer, W. (2000). Critical inquiry in a text-based environment: Computer conferencing in higher education. Internet and Higher Education, 2(2-3), 87-105.

Gunawardena, C. N., \& Zittle, F. J. (1997). Social presence as a predictor of satisfaction within a computer-mediated conferencing environment. American Journal of Distance Education, 11(3), 8-26.

Hew, K. F., \& Cheung, W. S. (2012). Student participation in online discussions: Challenges, solutions, and future research. Springer Science \& Business Media.

Holsti, O. R. (1969). Content analysis for the social sciences and humanities: Addison-Wesley Pub. Co.

Hou, H. T., \& Wu, S. Y. (2011). Analyzing the social knowledge construction behavioral patterns of an online synchronous collaborative discussion instructional activity using an instant messaging tool: A case study. Computers $\Theta^{2}$ Education, 57(2), 1459-1468.

Kanuka, H., Rourke, L., \& Laflamme, E. (2007). The influence of instructional methods on the quality of online discussion. British Journal of Educational Technology, 38(2), 260-271.

Lai, A. (2016). Mobile immersion: An experiment using mobile instant messenger to support second-language learning. Interactive Learning Environments, Available at: https://doi.org/10.1080/10494820.2015.1113706, 24(2), 277-290.

Lee, S. M. (2014). The relationships between higher order thinking skills, cognitive density, and social presence in online learning. The Internet and Higher Education, 21, 41-52.

Lees, S. W., \& Rine, D. C. (2004). Case study methodology designed research in software engineering methodology validation.

MI, G. M., \& Meerasa, S. S. (2016). Perceptions on M-learning through WhatsApp application. Journal of Education Technology in Health Sciences, 3(2), 57-60.

Naismith, L. (2007). Using text messaging to support administrative communication in higher education. Active Learning in Higher Education, 8(2), 155-171.

Quan-Haase, A., Cothrel, J., \& Wellman, B. (2005). Instant messaging for collaboration: A case study of a high-tech firm. Journal of Computer-Mediated Communication, $10(4)$, 00-00.

Rambe, P., \& Bere, A. (2013). Using mobile instant messaging to leverage learner participation and transform pedagogy at a South African university of technology. British Journal of Educational Technology, 44(4), 544-561.

Rau, P. L. P., Gao, Q., \& Wu, L. M. (2008). Using mobile communication technology in high school education: Motivation, pressure, and learning performance Computers $\Xi^{\circ}$ Education, $50(1), 1-22$.

Rodriguez, M. A. (2014). Content analysis as a method to assess online discussions for learning. SAGE Open 4(4), 2158244014559019.

Short, J., Williams, E., \& Christie, B. (1976). The social psychology of telecommunications. London: Wiley.

So, S. (2016). Mobile instant messaging support for teaching and learning in higher education. The Internet and Higher Education, 31, 32-42.

Statista. (2017). Number of monthly active WhatsApp users worldwide from April 2013 to January 2017 (in millions). Available from: https://www.statista.com/statistics/260819/number-of-monthly-active-whatsapp-users/. [Accessed May 20, 2017]

Tang, Y., \& Hew, K. F. (2017). Is mobile instant messaging (MIM) useful in education? Examining its technological, pedagogical, and social affordances. Educational Research Review, 21: 85-104. Available at: http://dx.doi.org/10.1016/j.edurev.2017.05.001.

Tencent. (2017). Tencent announces 2017 first quarter results. Available from: https://www.tencent.com/zhcn/articles/15000611495014502.pdf. [Accessed May 15000611495014520, 15000611495012017].

Wang, Y., Fang, W. C., Han, J., \& Chen, N. S. (2016). Exploring the affordances of WeChat for facilitating teaching, social and cognitive presence in semi-synchronous language exchange. Australasian Journal of Educational Technology, 32(4), 18-37.

Yin, R. K. (2003). Case study research: Design and methods: Applied social research methods series, biography. London: Sage Publications, 5 .

Zucker, D. M. (2009). How to do case study research. Teaching Research Methods in the Humanities and Social Sciences, 2. 